\title{
A CONSTRUÇÃO DAS DESIGUALDADES EM EDUCAÇÃO NO MUNICÍPIO DE ALCÂNTARA - MA
}

\author{
THE CONSTRUCTION OF INEQUALITIES IN EDUCATION IN THE \\ MUNICIPALITY OF ALCÂNTARA - MA
}

\author{
LA CONFORMACIÓN DE DESIGUALDADES EDUCATIVAS EN EL MUNICIPIO \\ DE ALCÂNTARA EN MARANHÃO
}

Ricardo Costa de Sousa ${ }^{1}$

\begin{abstract}
RESUMO:
O presente artigo trata da influência das teorias raciais na construção das desigualdades em educação no Município de Alcântara, Maranhão. Essa temática expressa à urgência da criação e implementação de ações afirmativas na busca pela equidade racial em educação. Tem-se como perspectiva teórica o Materialismo Histórico, pois, possibilita pensar as contradições, os conflitos e os processos históricos que marcaram e marcam a dinamicidade das desigualdades educacionais no Brasil. Nesse sentido, trata-se, em um primeiro momento, das teorias raciais na perspectiva biológica, antropológica e sociológica, e, em um segundo momento, trata-se das desigualdades raciais na educação em Alcântara para sinalizar a emergência de ações afirmativas. A pesquisa desenvolvida é de cunho bibliográfico e documental, inclusive documental-estatístico, sendo consultados livros e periódicos, assim como documentos estatísticos obtidos no site do IBGE. Os dados demonstram que as desigualdades entre brancos e negros continuam ainda acentuadas no Município de Alcântara, MA.
\end{abstract}

Palavras-Chaves: Teorias raciais. Desigualdades em educação. Alcântara.

\begin{abstract}
:
This article deals about the influence of racial theories in the construction of inequalities in education in the Municipality of Alcântara, State of Maranhão. This theme expresses the urgency of creating and implementing affirmative actions in the search for racial equity in education. The theoretical perspective is based on Historical Materialism, because, it makes possible to think about the contradictions, conflicts and historical processes that have marked and mark the dynamics of educational inequalities in Brazil. In this sense, it deals, at first, about racial theories from a biological, anthropological and sociological perspective, and, in a second moment, it deals about racial inequalities in education in Alcântara to signal the emergence of affirmative actions. The research developed is bibliographic and documentary,
\end{abstract}

${ }^{1}$ Pós- doutorando em Educação pela Universidade do Oeste do Estado de Santa Catarina - UNOESC. Militante do Centro de Cultura Negra Negro Cosme-CCNNC/Imperatriz: MA. E-mail: ricardo_lut@hotmail.com. 
including documentary-statistical, with books and periodicals being consulted, as well as statistical documents obtained on the IBGE website. The data show that the inequalities between whites and blacks are still accentuated, in the Municipality of Alcântara, MA.

Keywords: Racial theories. Inequalities in education. Alcântara.

\section{RESUMEN:}

Este articulo trata de la influencia de las teorías raciales en la conformación de desigualdades educativas en el municipio de Alcântara en Maranhão. Esta temática evidencia la urgente necesidad de crear e implementar acciones afirmativas en la búsqueda por una equidad racial en la educación. Se toma el Materialismo Histórico como perspectiva teórica, pues, permite pensar las contradicciones, conflictos y procesos históricos que han marcado la dinámica de las desigualdades en Brasil. En este sentido, un primer momento trata de las teorías raciales desde una perspectiva biológica, antropológica y sociológica; en un segundo momento se tratan las desigualdades raciales en la educación en el municipio de Alcântara que resaltan la necesidad de acciones afirmativas. La investigación desarrollada es a partir de información bibliográfica y documental, incluso documental-estadística, siendo consultados libros, periódicos, así como documentos estadísticos obtenidos en el sitio web del IGBE. Los datos demuestran que las desigualdades entre blancos y negros aún son acentuadas, en el municipio de Alcântara, MA.

Palabras clave: Teorías raciales. Desigualdades en educación. Alcântara.

\section{INTRODUÇÃO}

Primeiramente, é importante ressaltar que os conceitos de raça, racismo, discriminação, discriminação racial, preconceito e preconceito racial são de extrema relevância, no sentido de apresentar a dinâmica das relações raciais, como bem demonstram às produções de Munanga (2000), Cavalleiro (2000), Jaccoud e Beghin (2002), Cashmore (2000), dentre outros. Conceitos estes que perpassam as teorias raciais sob a perspectiva biológica, antropológica e sociológica, de interesse maior neste escrito.

Assim, abordam-se como essas teorias influenciaram e/ou operaram na construção das desigualdades educacionais, para então, ressaltar a importância das ações afirmativas enquanto mecanismo de equidade. Tem-se como perspectiva teórica o Materialismo Histórico, pois, possibilita pensar as contradições, os conflitos e os processos históricos que marcaram e marcam a dinamicidade das desigualdades educacionais no Brasil, e, especialmente no Município de Alcântara.

O racismo na perspectiva biológica foi marco de discussões que ainda hoje, apesar dos estudos sobre genética, continuam a legitimar as desigualdades entre brancos e negros. A 
hierarquização racial, ao estabelecer escalas de valores entre as raças, legitimou, a partir da perspectiva biológica, a ideia de inferioridade, incapacidade e degenerescência da raça negra.

Em relação à perspectiva antropológica, estes, tentaram negar o uso do termo raça, visto que, biologicamente, raça não existe. Desse modo, os antropólogos tomaram o termo cultura, considerando-o como capaz de analisar a sociedade em sua totalidade, assim como as relações que esta estabelece historicamente com determinados grupos sociais.

De fato, se os antropólogos tivessem tentado "sepultar" o termo raça, ou mesmo se o tivessem "sepultado", ele seria exumado pelo movimento negro, ressurgindo com mais força, como símbolo de identidade, e de afirmação identitária. Nessa perspectiva, o termo raça não biologizado é uma construção social.

Na consulta aos dados disponibilizados pelo IBGE (2010), Alcântara consta com uma população de 21.851 mil habitantes, destes, 3.095 mil são recenseados como brancos e 18.626 mil habitantes são recenseados como negros (soma de pardos e pretos), sinalizando uma população majoritariamente negra. Mesmo assim, os dados mostraram que as desigualdades entre brancos e negros continuam ainda acentuadas, tanto no Brasil, como mais especificamente, no Município de Alcântara, Estado do Maranhão, dado que, o país oferece um sistema educacional discriminatório, pois mesmo tempo em que garante o acesso à educação, cria mecanismos de exclusão.

\section{TEORIAS RACIAIS NA PERSPECTIVA BIOLÓGICA, ANTROPOLÓGICA E SOCIOLÓGICA}

O conceito de raça, tal como se conhece, é carregado de ideologias. A persistência da ideia de raça se valeu da biologia para justificar as teorias de hierarquização racial. Moura (1990) aponta a existência de uma biologização da história através de teorias tidas como científicas, criadas para justificarem a aventura colonialista, onde na hierarquização das raças, colocavam o negro no último patamar da escala racial.

O processo biologizante representa a pretensa seleção natural ao exemplificar que os mais aptos de uma espécie sobreviveriam e passariam adiante a sua informação genética, enquanto os mais fracos seriam eliminados. Dessa forma, a hierarquização racial legitimou, a partir da perspectiva biológica, a ideia de inferioridade, incapacidade e degenerescência da raça. 
A obra, a origem das espécies, do naturalista britânico Charles Darwin (1809-1882) fora o marco para a criação da teoria da evolução por meio da seleção natural e sexual que se transformou em paradigma na explicação de fenômenos biológicos e que inspirou teorias sociais (DEL CONT, 2008).

Contudo, Del Cont (2008), assegura que, Darwin evitou fazer qualquer consideração que sugerisse que o ser humano também estaria sujeito aos mesmos princípios da seleção natural. Foi Herbet Spencer que cunhou a ideia de sobrevivência do mais forte. Ele defendia, também, a ideia de que o progresso humano tem como base a hierarquia racial, sem misturas.

A miscigenação, conforme aborda Del Cont (2008) era vista como inevitável o que levaria a raça humana aos maiores graus de degenerescência, tanto física quanto intelectual. O temor da mistura das raças. Contudo, o conde francês Arthur de Gobineau (1816-1882), e seus adeptos estavam certos da futura dominância da raça branca sobre o resto do mundo. E é no sentido de defender a retomada da raça ariana, do seu passado puro, que ele se torna o símbolo e proclamador do racismo biológico.

De acordo com Del Cont (2008), Galton, fundador da eugenia, procurou melhorar as características das pessoas a partir da seleção das melhores espécies, com o propósito de impedir a proliferação de características consideradas degenerativas. Neste sentido, o termo "eugenia" ou "bem nascido" tem como princípio estimular a reprodução das melhores espécies, onde, se evidencia claramente que, as propostas eugênicas têm em sua essência posições racistas.

O melhoramento genético segundo Petruccelli (1996) foi conforme, os intelectuais uma inspiração, visto que, a desigualdade e a heterogeneidade racial eram consideradas um agravante que, para ser sanado, requereria que fossem adotadas medidas de embranquecimento da população e de incentivo à imigração europeia, o que resultaria em uma população mestiça. Arthur de Gobineau apud Petruccelli (1996, p. 135), referindo-se a qualquer tipo de população mestiça, comenta que "uma tal população constituía, para ele, um povo degenerado "desde que não conserva, nas suas veias, o mesmo sangue original que sucessivas misturas fizeram, gradualmente, modificar seu valor".

Desse modo, a importância de se manter a pureza do sangue, isto é, manter a originalidade vitimada pela miscigenação. Em torno desse argumento, a eugenia poderia contribuir ao afirmar que as sucessivas misturas antagônicas favoreceriam o crescimento de raça degenerada, inferior e dotada de incapacidade intelectual.

A solução encontrada foi estimular os casamentos dos melhores membros da sociedade entre si, ou seja, casamentos entre linhagens consideradas eugenicamente qualificadas, nas 
quais passariam de geração a geração as melhores características físicas, comportamentais, assim como as habilidades intelectuais.

A literatura produzida demonstra que as pessoas eram conhecedoras das teorias europeias que circulavam e, afirmavam sobre a inferioridade dos negros e mestiços, a degenerescência da raça, e tantos outros discursos. Contudo, o racismo é um fenômeno de longa duração, que passa também pela perspectiva antropológica e sociológica, quer dizer, é um forte indicador na construção das desigualdades educacionais.

Quanto às teorias raciais na perspectiva antropológicas os estudos contribuem de forma significativa para o entendimento dos discursos que são disseminados e carregados de ideologias preconceituosas, que segregam, excluem e inferiorizam a população negra. Partindo desse entendimento, é importante apontar a construção e desconstrução de conceitos e discursos empregados pela Antropologia.

Segundo Heilborn, Araújo e Barreto (2010), cada sociedade tinha formas próprias de organização e formava um sistema único e coerente em si mesmo, que abria caminho para uma concepção de cultura como um todo articulado, focando nas diferenças. Essa afirmativa das autoras só foi possível a partir do método etnográfico utilizado pelos antropólogos Franz Boas e Malinowski.

Primeiramente, destaca-se, o termo cultura, defendido pelos antropólogos em contraposição ao termo raça. A desconstrução do termo raça pela ideia de cultura é o principal discurso abordado pela Antropologia. Foi o que fez Gilberto Freyre quando desloca o eixo da discussão, operando a passagem do conceito de raça para o conceito de cultura.

Heilborn, Araújo e Barreto (2010, p. 53) dizem que Franz Boas, buscando outra compreensão para o termo raça, defende a ausência de um "determinismo racial". Nesse sentido, os antropólogos tentaram refinar o conceito de cultura por duas vertentes, "uma na direção da cultura como totalidade, como expressão de uma dada sociedade em todas a suas esferas [...]. Outra, na cultura como produto histórico, cujo desenvolvimento depende das trocas e relações internas ao grupo e entre grupos num dado meio geográfico.

Afastando-se do conceito de raça no estudo das sociedades, passou-se a discutir o conceito de cultura na perspectiva antropológica, tido como objeto de estudo nas supostas "sociedades primitivas". Nesse sentido, de acordo com o conceito cunhado pelas Ciências Sociais, compreende-se que a Antropologia aponta a "cultura" como alternativa à ideia de raça, não biologizado. Contudo, é importante dizer que a substituição do termo raça por cultura não foi uma passagem nada tranquila, mas sim permeada de conflitos.

Outro conceito que procura substituir o termo raça, é o de etnia, termo complexo e 
ambíguo. Valente (1987, p.8) diz que "ele é definido como grupo biológico e culturalmente homogêneo. No entanto é muito difícil perceber a homogeneidade cultural que distinguiria, de maneira específica, um grupo dos demais". Isso, em razão de que, segundo Valente (1987, p.8) "um grupo étnico afirma sua diferença a partir de dados culturais que podem ser partilhados com outros grupos".

O termo "étnico" foi empregado para designar diferentes realidades, criando um malestar teórico que contribui para aumentar, ainda mais, a proximidade do conceito de etnia com a noção de raça e que o termo etnia seria uma tentativa de fugir a uma forma de pensamento biologizante, naturalizadas nas expressões como "problemas étnicos" ou "minorias étnicas". Nesse sentido, a identidade étnica não depende apenas da autoidentificação do grupo, mas também de ser identificado como tal por outros grupos. Além disso, a identidade étnica pode ser definida pelo sentimento de pertença a um grupo decorrente da partilha do modo de vida e de processos históricos comuns.

É importante salientar que as construções conceituais são dinâmicas e precisam ser compreendidas ao longo de um período histórico. A esse respeito, Guimarães (2003, p. 95) afirma que "qualquer conceito, seja analítico, seja nativo, só faz sentido no contexto ou de uma teoria específica ou de um momento histórico específico”.

Considerando a importância da Sociologia para a compreensão do termo raça, Guimarães (2003, p. 96) conceitua dizendo que "são discursos sobre as origens de um grupo, que usam termos que remetem à transmissão de traços fisionômicos, qualidades morais, intelectuais, psicológicas”. Outro discurso é a identificação de pessoas com um grupo enorme de indivíduos, podendo ser nomeado como grupo étnico como descrito. Dessa maneira, discutir sobre a questão racial sem antes considerar a perspectiva cultural seria uma perda para a compreensão do termo raça na perspectiva sociológica. Neste contexto, Heilborn, Araújo e Barreto (2010, p. 86) asseguravam que o termo raça "não condenava mais a nação", dado que, "substituída pela categoria "cultura", a democracia racial afirmava a convivência pacífica e igualitária entre os grupos raciais diferentes".

A expressão "democracia racial”, atribuída a Gilberto Freyre, através da obra Casagrande e senzala (2006), que coloca a escravidão no Brasil como sendo composta de senhores bondosos e escravos submissos, empaticamente harmônicos, desfazendo, com isso, a possibilidade de se ver o período no qual perdurou o escravismo como cheio de contradições agudas, sendo que a primeira e mais importante e que determinava todas as outras era a que existia entre senhores e escravos.

Alguns estudos raciais sustentam que o termo raça não desapareceu totalmente do 
discurso científico, não apenas do discurso da biologia, como também de todos os discursos que insistem em explicar a vida social em concorrência com a sociologia. Dessa forma, o termo raça é cientificamente um constructo social e deve ser estudado por um ramo próprio da Sociologia ou das Ciências Sociais.

Efetivamente, o racismo não existiria sem a ideia dos discursos científico e biológico, que tentaram explicar a vida social em concorrência com a Sociologia, pois, compreende-se, dessa forma, que os discursos de perspectiva biológica alicerçaram as bases de hierarquias nas sociedades. Logo porque, segundo Teodoro (1996, p. 99) “o problema do racismo não é somente brasileiro e sim global e que precisa ser combatido".

Na compreensão de Francisco (2006), o Brasil necessitava de um novo corpo social, de uma nova identidade, de um Estado que buscasse o desenvolvimento econômico industrial. Contudo, as questões raciais não eram ponderadas com tanta veemência quanto à questão do desenvolvimento econômico industrial, pois o Brasil pregava a harmonia racial e social.

Considerando o período do Estado Novo, Moore (2007, p. 25) diz que "nação implica a noção de unidade, mas salienta que as disparidades socioeconômicas e raciais constatadas no Brasil constroem uma nítida e cruel polarização da população". Com a vigência do Estado Novo, o Brasil apresenta uma nova configuração da identidade cultural: uma identidade assumida pelo sentimento de pertencimento à nação brasileira. Ademais, o pertencimento nacional ou identidade nacional é um conjunto de representações, características da cultura de um povo, que permite reconhecê-lo e diferenciá-lo dos demais. Em síntese, é um constructo social. Contudo, essa afirmação identitária muito pouco contribuiu para a superação das desigualdades raciais, em especial na educação.

Cabe registrar os esforços empreendidos por estudiosos das relações raciais em desconstruir o "paraíso racial" criado e disseminado no Brasil, como país sem preconceitos ou discriminação racial, no qual o valor e o mérito individuais não seriam barrados pela pertença racial ou cor da pele. Assim, o termo "paraíso racial” utilizado por Guimarães é pertinente, pois caracteriza de forma clara e objetiva um mundo criado e elaborado pela elite brasileira na difusão de um discurso midiático que influenciou as pessoas no seu modo de agir e pensar uma determinada sociedade. Nas palavras de Costa (1999) não se pode negar que os intelectuais brasileiros do século XIX e do começo do século XX foram influenciados pelas ideias europeias sobre a inferioridade dos mestiços e a superioridade da raça branca.

Por certo, ao romper com os conceitos biológicos e assumir um conceito sociológico, o Movimento Negro Unificado - MNU passa a utilizar o termo raça, discurso corrente, aceito e absorvido pela sociedade brasileira. 


\section{DESIGUALDADES RACIAIS NA EDUCAÇÃO EM ALCÂNTARA}

As teorias raciais supracitadas forneceram elementos que foram e continuam sendo fortes mecanismos de produções e reprodução das desigualdades em educação. É possível perceber no discurso do Movimento Negro, como também em várias produções acadêmicas de fundo teórico e empírico, que os negros foram abandonados à própria sorte, uma vez que não houve, de imediato, políticas de integração da população negra no sistema capitalista de trabalho assalariado, bem como, na educação. Segundo Hasenbalg (1979) embora a educação no Brasil tenha sido a principal via para a população de cor, há boas razões para acreditar que quanto maior for o nível educacional, maior será a discriminação experimentada no mercado de trabalho.

De certo, mesmo que a população negra apresente níveis de instrução iguais e até superiores em relação à população branca, estes, recebem salários inferiores aos que destas. Esta mesma constatação é realizada por Munanga (1996, p. 83) quando diz que "os raros negros instruídos que escaparam dos trabalhos manuais menos remunerados e conseguiram ocupar posições reservadas aos brancos recebem salários inferiores aos colegas brancos do mesmo nível de formação".

Nascimento (1985) e Hasenbalg (1979) são unanimes em afirmar que, além de existirem desigualdades em todos os níveis de ensino, as desigualdades de oportunidades crescem exponencialmente ao se passar para níveis de ensino mais elevados, pois, desqualificar suas habilidades era uma forma de manter a ideologia racista da incapacidade, como também, de manter a população negra em níveis inferiores da hierarquia.

A literatura pesquisada indica que o Brasil enfrentou muito tardiamente o problema dos baixos índices educacionais de sua população, em especial da população de cor. Mesmo assim, a educação no Brasil continua sendo o principal meio de ascensão social para essa população, que é estigmatizada e marginalizada pela classe dominante, tanto no sistema produtivo, como no sistema escolar. Conforme Heilborn, Araújo e Barreto (2010, p. 139) “estar na escola significa não somente a possibilidade de estar diante de oportunidade de aumento de capital humano, mas também, dependendo da faixa etária, significa chances de permanecer por mais tempo nos bancos escolares". É o que demonstra os dados dos últimos censos demográficos, do aumento significativo de ingressos no sistema educacional (IBGE, 
2000, 2010). O que não significa a permanência no sistema escolar da população negra.

No site do IBGE $(2000,2010)$, é possível verificar a trajetória das taxas de analfabetismo para o conjunto populacional de Alcântara, nos censos de 2000 e 2010, em números absolutos e em porcentagem para a população de 5 anos ou mais, que sabem ler e escrever e, que não sabem ler e escrever, entendidos como analfabetos, segundo cor ou raça. Aqui, apresentam-se somente as taxas de analfabetismo entre brancos e negros (entendidos como a soma de pardos e pretos).

Segundo Galvão e Di Pierro (2007, p. 16) “a ampla maioria dos analfabetos é constituída por pessoas oriundas do campo, de municípios de pequeno porte, nascidas em famílias numerosas e muito pobres, cuja subsistência necessitou da mão-de-obra de todos os membros desde cedo". Possivelmente, ao que tudo indica e que, o trabalho precoce, aliada as dificuldades de acesso ou mesmo, da ausência de escolas no espaço rural foram impeditivos ou limitações para os estudos. O mesmo acontece em Alcântara, onde inúmeras famílias não tiveram acesso à escola e, quando tiveram, foram excluídas pelo sistema educacional ou mesmo pela extrema pobreza que constitui certamente um problema mais sério e mais grave do que o analfabetismo.

Os dados do IBGE, demonstram as desigualdades entre brancos e negros nos censos de 2000 e 2010. Para o censo de 2000, a taxa de analfabetismo para a população branca é de $26,6 \%$, enquanto, para a população negra, chega a $34,1 \%$, representando um distanciamento de 7,5 pontos percentuais entre brancos e negros (IBGE, 2000, 2010).

Contudo, no censo de 2010, a taxa de analfabetismo para a população branca é de 20,6\%, enquanto, para a população negra, a taxa é de $24,7 \%$, representando um distanciamento de apenas 4,1 pontos percentuais. Destaca-se que, no censo de 2010, as desigualdades educacionais diminuíram, mas persistem (IBGE, 2000, 2010).

Observa-se que nos censos de 2000 e 2010 a taxa de analfabetismo caiu em 9,4\% para a população negra. Uma queda significativa, é claro, se tomar a população branca nos censos de 2000 e 2010 em que a taxa de analfabetismo caiu em 6,0\% (IBGE, 2000, 2010).

Ao que tudo indica, as ações para implementação da Lei N. 10.639/2003, assim como outras políticas públicas, contribuíram para a queda do analfabetismo em Alcântara. Com efeito, tais ações voltaram-se especialmente para a população negra, que apresentava um alto nível de vulnerabilidade, especialmente quando residente em Comunidades Quilombolas. Merece destaque as Diretrizes do Plano Nacional de Educação que, no Art. $2^{\circ}$ inciso III, determina: "a superação das desigualdades educacionais, com ênfase na promoção da 
cidadania e na erradicação de todas as formas de discriminação" (BRASIL. 2014), assim como, na superação das desigualdades nos níveis de instrução, por cor ou raça.

Cabe dizer que, para o estudo do estado educacional, os organismos internacionais se servem de informações que concernem às pessoas de 10 anos e mais. Trata-se, aqui, do nível de instrução segundo a cor ou raça, no sentido de apresentar o retrato educacional, assim como sinalizar as desigualdades no município de Alcântara, para as pessoas de 10 anos ou mais, segundo o nível de instrução (sem instrução e fundamental incompleto, fundamental completo e médio incompleto, médio completo e superior incompleto, superior completo), por cor ou raça (brancas, pretas e pardas) em porcentagem do município de Alcântara, Maranhão.

Adentrando nos níveis de instrução por cor ou raça, considera-se relevante dizer que a universalização do atendimento escolar, como consta no Art. $2^{\circ}$, inciso II, da Lei $n^{\circ} 13.005$, de 25 de junho de 2014, é um dos grandes desafios, haja vista uma grande quantidade de pessoas que ainda não conseguiu concluir a educação básica (BRASIL, 2014).

Consta nos dados disponibilizados pelo IBGE (2010) que 60,4\% da população branca foi recenseada como "sem instrução e fundamental incompleto", enquanto para a população preta o percentual foi de 68,0\%. Dessa forma, pode-se entender que a população branca em percentuais apresenta as menores taxa de pessoas "sem instrução e fundamental incompleto", enquanto a população declarada parda chega até $69,2 \%$. Se somar, aqui, a população de pardos e pretos, as desigualdades educacionais seriam ainda mais acentuadas (IBGE, 2010).

Os dados apontam também que a população branca tem 18,8\% com "fundamental completo e médio incompleto", enquanto a população preta tem $14,8 \%$ e a população declarada parda $15 \%$. É visível que a população branca apresenta os maiores percentuais para esse nível de instrução (IBGE, 2010).

De acordo com Lei 9.394/1996, que estabelece as Diretrizes e Bases da Educação Nacional, deve-se assegurar, em primeiro lugar, o acesso ao ensino obrigatório (à conclusão do ensino fundamental) a todos os brasileiros, e, em seguida, os demais níveis e modalidades de ensino, como progressiva obrigatoriedade do ensino médio (BRASIL, 1996).

Para o ensino "médio completo e superior incompleto", a população branca apresenta $18,3 \%$, enquanto a população preta chega a $14,7 \%$ e a população parda a $13,8 \%$. Esse dado nos mostra que a população branca apresenta um elevado percentual de escolarização, enquanto as desigualdades entre a população preta e parda sinalizam em torno de $1 \%$ (IBGE, 2010).

No que concerne à população presente no ensino superior, temos 2,3\% para as pessoas brancas, $2,4 \%$ para as pessoas pretas e 1,8\% para as pessoas declaradas pardas. Fica evidente 
que a população preta no ensino superior é de um ponto percentual a mais que a população branca, a mesma ficando abaixo da população parda (IBGE, 2010). Contudo, se somássemos a população preta e parda, prática frequente em vários estudos estatísticos, teríamos, então, uma presença majoritária de pessoas negras no ensino superior em Alcântara.

Desse modo, a apresentação desses dados, possibilita a elaboração de Políticas Públicas para o enfrentamento das desigualdades educacionais, vivenciadas, em sua maioria, pela população negra. De modo geral, este artigo suscita a necessidade de elaboração de Ações Afirmativas que possibilitem minimizar as desigualdades, ou seja, diminuir as distâncias sociais entre negros e brancos, que continuam injustificáveis na sociedade atual. Em relação a essas disparidades Jaccoud e Beghin (2002, p. 46) apontam as ações afirmativas como sendo “medidas especiais e temporárias, tomadas pelo Estado e/ou pela iniciativa privada, espontânea ou compulsoriamente, com o objetivo de eliminar desigualdades historicamente acumuladas, garantindo a igualdade de oportunidade e tratamento". Partindo dessa premissa, a ação afirmativa consiste em dar tratamento preferencial àqueles que historicamente foram marginalizados de sorte a colocá-los em um nível de competição similar ao daqueles que historicamente se beneficiaram com sua exclusão, tanto no trabalho, quanto na educação.

Considera-se importante salientar a argumentação de Guimarães $(1999$, p. 63), quando diz que, "a falta de políticas públicas efetivas para reverter à situação marginal dos negros na sociedade brasileira acabou por reproduzir a ordem hierárquica diferenciadora entre brancos e negros, ampliando as desigualdades sociais”. Desse modo, não se trata de falta, mas sim de dar efetividade às Políticas Públicas, aqui, Ações Afirmativas de forma a minimizar as desigualdades educacionais que continuam sendo um grande entrave à realização do direito à educação, isto é, do acesso e permanência da população negra no espaço escolar.

\section{CONSIDERAÇÕES}

O texto tratou da construção das desigualdades em educação no município de Alcântara, Estado do Maranhão e demonstra a partir dos autores citados que, a dinâmica das relações raciais transitam pela perspectiva biológica, antropológica e sociológica. De maneira que, as teorias raciais influenciaram decisivamente nas desigualdades educacionais em Alcântara.

A pesquisa indicou que o racismo na perspectiva biológica foi marco de discussões que continuam a legitimar as desigualdades entre brancos e negros. Já em relação aos estudos 
antropológicos, estes, tentaram negar o uso do termo raça, visto que, biologicamente, raça não existe. Dessa maneira, os antropólogos tomaram o termo cultura, considerando-o como capaz de analisar a sociedade em sua totalidade.

Os dados sugerem que, se os antropólogos tivessem tentado "sepultar" o termo raça, ou mesmo se o tivessem "sepultado", ele seria exumado pelo movimento negro, ressurgindo com mais força, como símbolo de identidade, de afirmação e de sua ancestralidade. Nessa perspectiva, o termo raça não biologizado é uma construção social que busca desmascarar o mito da democracia racial no Brasil.

As teorias raciais apontaram para os mecanismos de reprodução das desigualdades raciais, especialmente na educação, quando desqualifica as habilidades e potencialidades da população negra, pois, os dados que constam no site do IBGE sinalizam que, as desigualdades entre brancos e negros continuam ainda acentuadas, no Município de Alcântara.

Por fim, pode-se afirmar que o país oferece um sistema educacional discriminatório que, ao mesmo tempo, garante o acesso à educação, cria mecanismos de exclusão, e que essa desigualdade não é um dato somente do presente, mas sim, histórico.

\section{REFERENCIAS}

BRASIL. Lei $\mathrm{n}^{\circ} 13.005$, de 25 de junho de 2014. Plano Nacional de Educação - PNE. Disponível em: https://www2.camara.leg.br/legin/fed/lei/2014/lei-13005-25-junho-2014778970-publicacaooriginal-144468-pl.html. Acesso em: 30 jul. 2019.

BRASIL. Lei 9.394, de 20 de dezembro de 1996. Estabelece as Diretrizes e Bases da Educação Nacional. Disponível em: <http://www.planalto.gov.br/ccivil_03/leis/19394.htm>. Acesso em: 30 jul. 2019

CASHMORE, Ellis. Dicionário de relações étnicas e raciais. São Paulo: Selo Negro, 2000.

CAVALLEIRO, Eliane. Do silêncio do lar ao silêncio escolar. Racismo, preconceito e discriminação na educação infantil. São Paulo: Contexto, 2000.

COSTA, Emília Viotti da. Da Monarquia à República. Momentos decisivos. In: COSTA, Emília Viotti da. O mito da democracia racial no Brasil 6. ed. São Paulo: Fundação Ed. UNESP, 1999.

DEL CONT, Valdeir. Francis Galton: eugenia e hereditariedade. SCIENTIAE Studia, São Paulo, v.6, n. 2, p.201-218, 2008. Disponível em: http://www.scielo.br/pdf/ss/v6n2/04 Acesso em: 02 abr. 2020. 
FRANCISCO, Dalmir. Comunicação, identidade cultural e racismo. In: FONSECA, Maria Nazareth Soares (org). Brasil afro-brasileiro. 2. ed. Belo Horizonte: Autêntica, 2006.

GALVÃO, Ana Maria de Oliveira; DI PIERRO, Maria Clara. Preconceito contra o analfabeto. São Paulo: Cortez, 2007.

GUIMARÃES, Antônio S. A. Como trabalhar com raça em sociologia. Educação e Pesquisa, São Paulo, v.29, n.1, p.97-107, jan./jun. 2003. Disponível em: http://www.scielo.br/pdf/ep/v29n1/a08v29n1.pdf. Acesso em: 02 abr. 2020.

GUIMARÃES, Antônio S. Racismo e Anti-Racismo no Brasil. São Paulo: FUSP, 1999.

HASENBALG, Carlos Alfredo. Discriminação e desigualdades raciais no Brasil. Rio de Janeiro: Edições Graal, 1979.

HEILBORN, Maria Luiza; ARAÚJO, Leila; BARRETO. Andreia. Gestão de Políticas Públicas em Gênero e Raça. GPP-GeR: módulo II. Rio de Janeiro: CEPESC; Secretaria de Políticas para as Mulheres, 2010.

IBGE, Censo demográfico 2000. Disponível em: <http://biblioteca.ibge.gov.br/visualizacao/periodicos/86/cd_2000_educacao_amostra.pdf >. Acesso em: 07 jul. 2019.

IBGE, Censo demográfico 2010. Disponível em: $<$ http://biblioteca.ibge.gov.br/visualizacao/periodicos/545/cd_2010_educacao_e_deslocame nto.pdf>. Acesso em: 07 jul. 2019.

JACCOUD, Luciana de Barros; BEGHIN, Nathalie. Desigualdades raciais no Brasil: um balanço da intervenção governamental. Brasília: Ipea, 2002.

MOORE, Carlos. Racismo \& Sociedade: novas bases epistemológicas para entender o racismo. Belo Horizonte: Mazza edições, 2007.

MOURA, Clóvis. As injustiças de Clio. O negro na historiografia brasileira. Belo Horizonte, Oficina de Livros, 1990.

MUNANGA, Kabengele. O anti-racismo no Brasil. In: MUNANGA, Kabengele. Estratégias e Políticas de combate à discriminação racial. São Paulo; Editora da USP: Estação Ciência, 1996.

MUNANGA, Kabengele. Uma abordagem conceitual das noções de raça, racismo, identidade e etnia. In: André Augusto P. Brandão (org). Programa de Educação sobre o negro na sociedade brasileira - PENESB, n 5. Niterói: EdUFF, 2000.

NASCIMENTO, Abdias. Combate ao racismo. Discursos e projetos de lei. Câmara dos Deputados. Centro de documentação e informação. Brasília, 1985.

PETRUCCELLI, José Luís. Doutrinas Francesas e o pensamento racial brasileiro, 1870 1930. Estudos Sociedade e Agricultura, n. 7, p. 134-149, dez.1996. 
TEODORO, Maria de Lourdes. Elementos básicos das políticas de combate ao racismo brasileiro. In: MUNANGA, Kabengele. Estratégias e Políticas de combate à discriminação racial. São Paulo; Editora da USP: Estação Ciência, 1996.

VALENTE. Ana Lúcia E. F. Ser negro no Brasil hoje. São Paulo: Editora Moderna, 1987. 